\title{
Enxertia de diferentes combinações de copas e porta-enxertos em maracujazeiros
}

\section{Grafting of different combinations of scions and rootstocks of passion fruit plants}

\author{
Verônica Andrade dos Santos ${ }^{1 *}$; José Darlan Ramos²; Edvan Alves Chagas; \\ Márcia Maria Dias ${ }^{4}$, Guilherme Locatelli ${ }^{5}$; Marcelo Caetano de Oliveira ${ }^{6}$
}

\section{Resumo}

\begin{abstract}
A utilização de porta-enxerto no cultivo do maracujazeiro tem como objetivo solucionar problemas relacionados a doenças causadas por patógenos do solo. A formação de mudas por este método poderá propiciar maior longevidade às plantas e menores perdas para o produtor. O objetivo do trabalho foi avaliar a enxertia das diferentes combinações copa/porta-enxerto, na formação de mudas utilizando os maracujazeiros Passiflora cincinnata e Passiflora alata como porta-enxertos para copas de maracujazeiros amarelo, doce e roxo. O delineamento experimental utilizado foi em blocos casualizados, em esquema fatorial $2 \times 3$, sendo dois porta-enxertos e três tipos de copas, com quatro repetições e dez plantas por parcela. O Passiflora cincinnata quando utilizado como porta-enxerto para os maracujazeiros amarelo, roxo e doce propiciou menor pegamento e menor desenvolvimento das mudas. A formação de mudas através da enxertia dos maracujazeiros amarelo e roxo sobre o Passiflora alata mostrou-se viável, para a maioria das características avaliadas.
\end{abstract}

Palavras-chave: Passiflora cincinnata, Passiflora alata, compatibilidade, produção de mudas

\begin{abstract}
The use of rootstock in the cultivation of passion fruit aims to solve problems related to diseases caused by soil-borne pathogens. The seedling production by this method may provide greater longevity for plants and smaller losses for the producer of passion fruit. The objective of this study was to evaluate the grafting of different canopy / rootstock, using Passiflora alata and Passiflora cincinnata as rootstocks for yellow, sweet and purple passion fruit plants. The experimental design was completely randomized in a factorial $2 \times 3$ scheme (two rootstocks and three types of scions), with four replications and ten plants per plot. The Passiflora cincinnata when used as rootstock for yellow, purple, and sweet passion fruit showed lower grafting success rate and seedling development. The formation of seedlings by grafting of yellow and purple passion fruit on Passiflora alata proved to be feasible for the majority of those characteristics.
\end{abstract}

Key words: Passiflora cincinnata, Passiflora alata, compatibility, propagation

\footnotetext{
${ }^{1}$ Eng $^{\mathrm{a}}$ Agr $^{\mathrm{a}}$, Pós-Doutoranda, Empresa Brasileira de Pesquisa Agropecuária, EMBRAPA/UFRR, Boa Vista, RR. E-mail: veronicaandrad@yhoo.com.br

2 Eng $^{\circ}$ Agr $^{\circ}$, Prof. Dr. do Dept ${ }^{\circ}$ de Agricultura, Universidade Federal de Lavras, UFLA, Lavras, MG. E-mail: darlan@dag.br

3 Eng ${ }^{\circ}$ Agr $^{\circ}$, Dr. Pesquisador da EMBRAPA, Boa Vista, RR, Bolsista de Produtividade do CNPq. E-mail: edvan.chagas@embrapa.br

4 Eng $^{\mathrm{a}}$ Agr $^{\mathrm{a}}$, Universidade Estadual de Montes Claros, UNIMONTES, Montes Claros/MG. E-mail: dias@yahoo.com.br

5 Discente do Curso de Mestrado em Fitotecnia, UFLA, Lavras, MG. E-mail: guilherme_locatelli_@hotmail.com

${ }^{6}$ Eng $^{\mathrm{o}}$ Agr $^{\mathrm{o}}$, Pós-Doutorando, Dept ${ }^{\mathrm{o}}$ de Agricultura, UFLA, Lavras, MG. E-mail: caetanocaldas@hotmail.com

Autor para correspondência
} 


\section{Introdução}

O maracujazeiro é originário da América Tropical e possui mais de 150 espécies nativas do Brasil. As mais conhecidas e de maior valor na exploração comercial são Passiflora edulis Sims (maracujás amarelo e roxo) (OLIVEIRA JÚNIOR et al., 2010).

Com a grande biodiversidade do número de espécies nativas de maracujazeiros, além do consumo in natura a espécie também pode ser utilizada na produção de defensivos, indústria farmacêutica e principalmente nos programas de melhoramento genético, pois algumas destas apresentam resistência à ação dos patógenos (CORRÊA et al., 2010). Embora as pesquisas com maracujazeiros estejam amplamente dirigidas às espécies cultivadas, várias espécies silvestres de maracujazeiros com potencial agronômico não têm recebido atenção da pesquisa, como por exemplo, Passiflora cincinnata, de ocorrência espontânea na região semiárida do Nordeste brasileiro (ARAÚJO; SILVA; QUEIROZ, 2008).

A espécie Passiflora cincinnata é silvestre não comercial, popularmente conhecida como maracujá mochila, maracujá-do-mato ou maracujá-tubarão. É considerada potencialmente importante para uso como porta-enxerto, uma vez que apresenta tolerância às doenças e nematóides (APONTE; JÁUREGUI, 2004). O Passiflora alata também é resistente ao Fusarium oxysporum f. passiflorae e tolerante a Phytophtora spp. e Fusarium solani, (FISCHER et al., 2005). Sendo uma espécie promissora para ser utilizada como porta enxertos para o maracujazeiro amarelo (OLIVEIRA JÚNIOR et al., 2010).

A propagação do maracujazeiro-amarelo é tradicionalmente realizada por sementes, e devido à variabilidade genética inerente ao método, a maioria dos pomares é desuniforme, em termos de produção e qualidade dos frutos, o que resulta em baixa produtividade (SILVA et al., 2011). Nos últimos anos ocorreu aumento da produção do maracujazeiro devido à expansão de áreas agrícolas, no entanto isto nem sempre resulta em incremento da produtividade e da qualidade dos frutos (CAVALCANTE et al., 2009). Segundo Aguiar et al., (2010), o surgimento de novas áreas de cultivo e a expansão da cultura do maracujazeiro propiciaram o aparecimento de diversos problemas fitossanitários, reduzindo a vida útil dos pomares.

Desta forma, a produção e a utilização de mudas de alta qualidade tornam-se uma estratégia para a melhoria do pomar, propiciando maior competitividade da produção (AGUIAR et al., 2010). A enxertia é uma técnica estudada por vários autores para a propagação do maracujazeiro (CHAVES et al., 2004; LIMA; TRINDADE, 2004; RONCATTO et al., 2011). Essa prática pode contribuir para o estabelecimento de pomares tecnicamente superiores se comparados àqueles formados pelo sistema convencional, seja em função do controle de doenças, principalmente à morte prematura de plantas e nematóides, através do uso de porta-enxertos resistentes ou tolerantes (RONCATTO; OLIVEIRA; RUGGIERO, 2004).

Em relação à escolha do método, os tipos mais utilizados de enxertia para o maracujazeiro amarelo sobre o maracujazeiro doce são fenda cheia e inglês simples, com taxa de pegamento superior aos 90\%, em ambos os processos (SILVA et al., 2011). No entanto Santos et al. (2011) relatam que tanto os métodos de enxertia quanto a época após a emergência das plântulas influenciam na porcentagem de pegamento do enxerto.

Quanto à enxertia utilizando espécies silvestres, há diferentes informações sobre a porcentagem de pegamento, pois a maioria dessas espécies possuem diâmetros pouco evoluídos, ocorrendo a incompatibilidade entre as espessuras dos diâmetros do porta-enxerto e enxerto sendo necessário um estudo mais detalhado sobre a viabilidade, compatibilidade entre as espécies, tempo de formação e desenvolvimento das mudas em viveiro. Diante do exposto, o trabalho teve como objetivo 
avaliar a enxertia de diferentes combinações copa/porta-enxerto, para obtenção de mudas dos maracujazeiros amarelo, doce e roxo, utilizando Passiflora cincinnata e Passiflora alata como porta-enxertos.

\section{Material e Métodos}

O experimento foi conduzido em telado tipo sombrite com $50 \%$ de luminosidade localizado no Departamento de Agricultura, setor de Fruticultura da Universidade Federal de Lavras, Minas Gerais no período de fevereiro a maio de 2010. O clima da região é do tipo $\mathrm{Cwb}$, conforme a classificação climática de Köeppen (ANTUNES, 1986) com duas estações definidas, seca de abril a setembro e chuvosa de outubro a março.

Os porta-enxertos e copas foram formadas através de sementes das espécies Passiflora alata, Passiflora edulis Sims (maracujás amarelo e roxo) e Passiflora cincinnata, provenientes da Embrapa Mandioca e Fruticultura em Cruz das Almas, BA. A semeadura foi realizada em bandejas de isopor de 72 células, contendo o substrato comercial Plantmax $^{\circledR}$ para todas as espécies. O delineamento experimental utilizado foi em blocos casualizados, em esquema fatorial $2 \times 3$, dois porta-enxertos Passiflora cincinnata e Passiflora alata), e três copas, Passiflora alata e Passiflora edulis (maracujás de casca amarela e roxa), quatro repetições e dez plantas por parcela.

O Passiflora cincinnata possui maior período de germinação, por isso foi semeado 20 dias antes dos demais. Quando o Passiflora cincinnata estava com 50 dias e as demais plantas com 30 dias após a emergência das plântulas, e os porta-enxertos e enxertos possuíam em média $5 \mathrm{~cm}$ de altura e dois pares de folhas definitivas, efetuaram-se as enxertias.

Foi utilizado o método de enxertia por garfagem tipo inglês simples e para isto decepou-se o caule dos porta-enxertos, Passiflora alata e Passiflora cincinnata, abaixo do primeiro par de folhas, abriu- se um corte em bisel $(0,5 \mathrm{~cm})$. Deceparam-se as plantas dos enxertos, maracujazeiro-amarelo, doce e roxo, para a formação da copa com as mesmas espessuras de diâmetros dos porta- enxertos, a uma altura de $0,5 \mathrm{~cm}$ acima do colo das plantas e fezse uma cunha em bisel simples, utilizando-se uma lâmina de platina bem afiada do tipo "bisturi". Após a preparação de ambos, juntaram-se a copa e o portaenxerto de forma a coincidirem os tecidos cambiais, utilizou-se de fita adesiva transparente para envolver a região da enxertia. Logo após foi colocado um saco de polietileno $(5 \times 15 \mathrm{~cm})$ transparente para evitar o ressecamento e uma estaca de $10 \mathrm{~cm}$ como tutor para não ocorrer quebra das partes enxertadas durante a irrigação.

Aos 15 dias após a enxertia removeu-se o saco de polietileno dos enxertos e aos vinte dias retirouse a fita adesiva dos enxertos. O sistema de irrigação adotado foi por microaspersão, duas vezes ao dia, pela manhã e à tarde, por 30 minutos cada período. As temperaturas e precipitações durante o período experimental encontram-se na (Figura 1).

A porcentagem de pegamento das plantas foi avaliada aos 20 dias após a enxertia, observando-se após a retirada da fita adesiva se a copa utilizada encontrava-se da mesma cor que o porta - enxerto, sem escurecimento e cicatrizado. As medidas de altura, comprimento das raízes, diâmetro do porta - enxerto e da copa, contagem de folhas, peso da massa seca da parte aérea e de raízes foram realizadas 45 dias após a enxertia. Para determinar a altura das plantas foi utilizada régua graduada e para determinar o diâmetro a $0,5 \mathrm{~cm}$ acima e abaixo da fixação do porta-enxerto e copa utilizou-se paquímetro digital. A massa seca da parte aérea e raízes foram obtidas através da secagem das plantas em estufa de circulação forçada aos $60^{\circ} \mathrm{C}$ durante 48 horas e trituradas em moinho próprio do tipo macro de rotor vertical com facas móveis e fixas.

Os resultados obtidos foram submetidos à análise de variância e as médias comparadas pelo teste Tukey em 5\% de probabilidade, utilizando o software $\operatorname{SISVAR}^{\circledR}$ (FERREIRA, 2010). 
Figura 1. Porcentagem de pegamento em mudas enxertadas de maracujazeiros amarelo, roxo e doce sobre o Passiflora alata e Passiflora cincinnata. Lavras- MG, 2010.

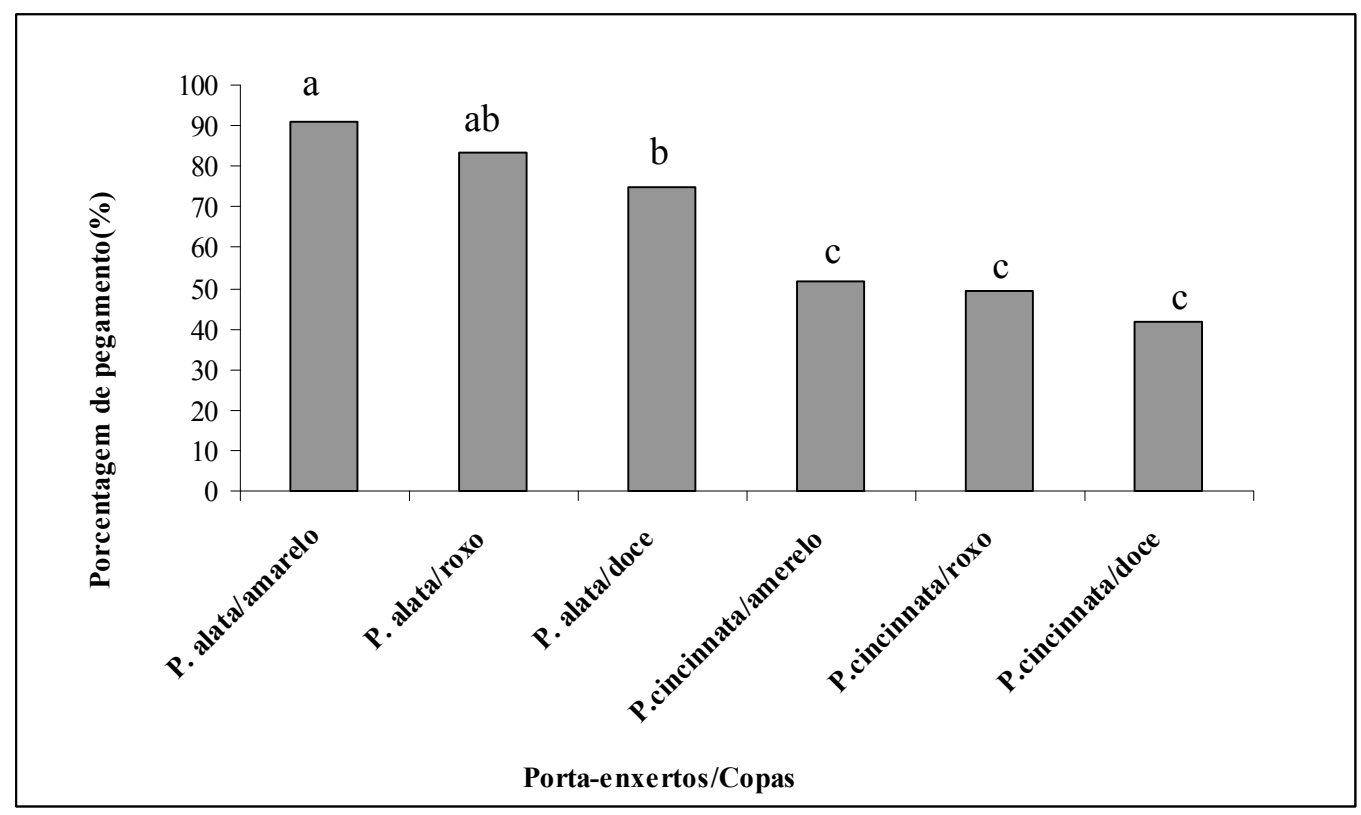

Letras distintas minúsculas na coluna diferem entre si, pelo teste de Tukey $\mathrm{P}<0,05$ ).

Fonte: Elaboração dos autores.

\section{Resultados e Discussão}

Apesar da interação porta-enxerto e diferentes copas não exercer efeitos significativos sobre nenhuma das variáveis avaliadas, os diferentes porta-enxertos exerceram efeitos isolados sobre todas as variáveis estudadas (Tabela 1). Constata-se também que dentre todas as variáveis estudadas a matéria seca da parte aérea das plantas foi a única que sofreu interferência estatística dos diferentes tipos de copas.

Verificou-se que o Passiflora alata como portaenxerto para os maracujazeiros amarelo, doce e roxo obtiveram média de pegamento de $83.1 \%$ (Figura 1).

Observa-se semelhança em relação ao pegamento das diferentes tipos de copas utilizadas estatisticamente semelhantes, o maracujazeiro- amarelo obteve $91 \%$ de pegamento, $83,8 \%$ para o maracujazeiro roxo e $75 \%$ para o maracujazeiro doce sobre o Passiflora alata. Pode-se afirmar que os materiais enxertados sobre este porta enxerto apresentaram também plantas mais altas, espessura maior do diâmetro dos porta-enxertos e das copas, facilitando com isto, a sobrevivência das mudas.

Resultados obtidos por Lenza et al. (2009) em que o Passiflora alata apresentou 95\%, Passiflora gibertii com 93\%, 'FB200' com 92\% e Passiflora nitida com $90 \%$ de pegamento. O Passiflora coccinea espécie silvestre alcançou um menor índice, com $65 \%$ de pegamento. Ressalta-se que estes autores utilizaram à técnica de enxertia hipocotiledonar, um tipo de enxertia em que se utilizam plântulas obtidas a partir de sementes, as médias de temperaturas máximas durante as enxertias foram de $28^{\circ} \mathrm{C}$. 
Tabela 1. Resumo da análise de variância para efeito em porta-enxertos e copas na formação de mudas de maracujazeiros, $\mathrm{P}=$ pegamento da enxertia, $\mathrm{H}=$ altura de mudas $(\mathrm{cm}), \mathrm{DPE}=$ diâmetro do porta-enxerto, $\mathrm{DCP}=$ diâmetro da copa $(\mathrm{mm}), \mathrm{NF}=$ número de folhas, $\mathrm{CPR}=$ comprimento da raiz $(\mathrm{cm}), \mathrm{MSR}=$ massa seca de raiz $(\mathrm{g}), \mathrm{MSPA}=$ massa seca da parte aérea (g). Lavras-MG, 2010.

\begin{tabular}{cccccccccc}
\hline \multirow{2}{*}{ F V } & GL & \multicolumn{7}{c}{ QUADRADOS MÉDIOS } \\
\cline { 3 - 9 } & & $\mathrm{P}$ & $\begin{array}{c}\mathrm{H} \\
(\mathrm{cm})\end{array}$ & $\begin{array}{c}\text { DPE } \\
(\mathrm{mm})\end{array}$ & $\begin{array}{c}\text { DCP } \\
(\mathrm{mm})\end{array}$ & NF & $\begin{array}{c}\text { CPR } \\
(\mathrm{cm})\end{array}$ & $\begin{array}{c}\text { MSR } \\
(\mathrm{g})\end{array}$ & $\begin{array}{c}\text { MSPA } \\
(\mathrm{g})\end{array}$ \\
\hline PE & 1 & $24,00^{* *}$ & $83,25^{* *}$ & $4,166^{* *}$ & $0,920^{*}$ & $16,83^{* *}$ & $458,50^{* *}$ & $5,900^{* *}$ & $22,62^{* *}$ \\
CP & 2 & $1,625^{\text {ns }}$ & $2,51^{\text {ns }}$ & $0,245^{\text {ns }}$ & $0,008^{\text {ns }}$ & $1,525^{\text {ns }}$ & 24,191 ns & $0,498^{\text {ns }}$ & $3,545^{* *}$ \\
PE x CP & 2 & $1,125^{\text {ns }}$ & $0,346^{\text {ns }}$ & $0,426^{\text {ns }}$ & $0,575^{\text {ns }}$ & $0,301^{\text {ns }}$ & $15,070^{\text {ns }}$ & $0,530^{\text {ns }}$ & $0,142^{\text {ns }}$ \\
Bloco & 3 & 1,00 & 1,864 & 0,087 & 0,204 & 0,624 & 12,374 & 0.423 & 1,252 \\
Erro & 15 & 9,50 & 3,983 & 0,091 & 0,188 & 1,699 & 10,312 & 0.3204 & 0,390 \\
CV $\%$ & - & 19,90 & 21,80 & 12,07 & 14,89 & 33,25 & 24,63 & 23,39 & 20,80 \\
\hline
\end{tabular}

${ }^{* *}$ Efeito significativo pelo teste $\mathrm{F}$ em nível $1 \%$ de probabilidade. ${ }^{\text {ns }}$ - Efeito não significativo pelo teste $\mathrm{F}$.

Fonte: Elaboração dos autores.

Quando se utilizou o Passiflora cinicinnata com os maracujazeiros amarelo, roxo e doce ocorreu um pegamento de 51, 8, 49,5 e 41,6\% respectivamente (Figura 1,) além da temperatura essa diferença em relação ao Passiflora alata, pode estar associada também a maior lignificação dos tecidos desta espécie dificultando a soldadura das partes enxertadas, causando uma possível incompatibilidade de diâmetros do Passiflora cincinnata com os diâmetros das copas, embora se tenha o cuidado de eleger os diâmetros semelhantes de ambas as partes, na ocasião da execução da enxertia, como a característica do caule desta espécie possuir lignificação dos tecidos no início de sua formação, motivo que pode ser decisivo nos resultados observados. Isso mostra que não são todas as espécies e variedades que têm afinidade quanto à técnica de enxertia. Apesar do baixo pegamento, esses resultados estão acima dos encontrados por Rocatto et al., (2011) trabalharam com diferentes espécies de maracujazeiros e diferentes combinações de copa e porta-enxerto obtiveram baixo índice de pegamento quando utilizaram a combinação FB 100 sobre Passiflora alata, não alcançando 30\%.
Há conflitos de informações na literatura relacionada à porcentagem de pegamento, entre espécies de maracujazeiros utilizadas como portaenxertos e enxertos, em que registram-se grandes diferenças quando se utiliza o mesmo método de enxertia e a mesma combinação enxerto/portaenxerto.

Pelos resultados apresentados na (Tabela 2), percebem-se a superioridade do porta-enxerto Passiflora alata sobre todas as variáveis avaliadas em relação a Passiflora cincinnata para as características de altura das mudas, diâmetros, número de folhas, comprimento de raízes, massa seca das raízes e parte aérea.

A altura das mudas requer atenção, pois quando se utilizou o Passifora alata como porta- enxerto houve um acréscimo de $3,72 \mathrm{~cm}$ em relação as mudas enxertadas sobre o Passifora cincinnata para todas as diferentes copas. O menor crescimento das mudas enxertadas no Passiflora cincinnata pode está relacionado ao lento desenvolvimento dessa espécie. Para Nogueira Filho et al. (2010), a grande variabilidade do número de folhas em maracujazeiro pode ser devida à fatores não inerentes ao crescimento. 
Tabela 2. Desenvolvimento vegetativo das mudas de maracujazeiros amarelo, roxo e doce enxertados em Passiflora cincinnata e Passiflora alata. Lavras - MG, 2010.

\begin{tabular}{cccccccc}
\hline $\begin{array}{c}\text { PORTA- } \\
\text { ENXERTOS }\end{array}$ & $\mathrm{H}(\mathrm{cm})$ & $\begin{array}{c}\text { DPE } \\
(\mathrm{mm})\end{array}$ & $\begin{array}{c}\mathrm{DCP} \\
(\mathrm{mm})\end{array}$ & $\mathrm{NF}$ & $\begin{array}{c}\text { CPR } \\
(\mathrm{cm})\end{array}$ & $\begin{array}{c}\text { MSR } \\
(\mathrm{g})\end{array}$ & $\begin{array}{c}\text { MSPA } \\
(\mathrm{g})\end{array}$ \\
\hline $\begin{array}{c}\text { Passiflora } \\
\text { cincinnata }\end{array}$ & $7,29 \mathrm{~b}$ & $2,58 \mathrm{~b}$ & $2,71 \mathrm{~b}$ & $3,08 \mathrm{~b}$ & $8,66 \mathrm{~b}$ & $1,78 \mathrm{~b}$ & $2,26 \mathrm{~b}$ \\
\hline Passiflora alata & $11,01 \mathrm{a}$ & $2,91 \mathrm{a}$ & $3,31 \mathrm{a}$ & $5,75 \mathrm{a}$ & $17,40 \mathrm{a}$ & $2,92 \mathrm{a}$ & $4,69 \mathrm{a}$ \\
\hline CV $(\%)$ & 21,80 & 12,07 & 14,89 & 23,25 & 24,63 & 23,96 & 20,80 \\
\hline
\end{tabular}

Médias com a mesma letra na coluna não diferem entre sí pelo teste Tukey, a $5 \%$ de probabilidade.

$\mathrm{H}=$ altura de mudas $(\mathrm{cm}), \mathrm{DPE}=$ Diâmetro do porta-enxerto $(\mathrm{mm}), \mathrm{DCP}=$ diâmetro da copa $(\mathrm{mm}), \mathrm{NF}=$ número de folhas, $\mathrm{CPR}=$ comprimento de raízes $(\mathrm{cm}), \mathrm{MSR}=$ massa seca de raízes e MSPA=massa seca da parte aérea $(\mathrm{g})$.

Fonte: Elaboração dos autores.

Em relação ao comprimento do sistema radicular do Passiflora alata foi de $8,74 \mathrm{~cm}$ maior em relação ao cincinnata. Essa variável serve como referência de eficiência na formação de mudas. $\mathrm{O}$ desenvolvimento do sistema radicular influencia diretamente na capacidade de absorção de água e de nutrientes, consequentemente plântulas com raízes maiores resultarão em mudas mais vigorosas e mais viáveis ao cultivo. O sistema radicular também dá suporte à massa verde produzida e para isto é necessário um bom desenvolvimento de raízes (SOUZA et al., 2006). Nesse sentido, segundo Caldeira et al. (2008), deve-se dizer que a relação parte área e raiz nas mudas deve ser de 2:1 e a relação raiz e parte aérea 1:2. É importante analisar essa relação quando as mudas vão para o campo, pois a parte aérea das mudas não dever ser muito superior que a da raiz em função dos possíveis problemas no que se refere à absorção de água para a parte aérea.

Vale salientar que as características avaliadas são importantes para sobrevivência das mudas, com isto pode-se dizer que o Passiflora alata apresenta características de formação de mudas excelentes, e que na fase inicial de desenvolvimento não há evidências de incompatibilidade entre $o$ porta-enxerto maracujazeiro-doce e os enxertos utilizados. De acordo com Santos et al., (2011) o sucesso da enxertia em maracujazeiro está tanto na uniformidade dos diâmetros utilizados, idade das mudas e épocas em que se realiza a enxertia, estes autores também descrevem que quanto mais jovem a plântula, melhor o pegamento das partes enxertadas.

Verifica-se também maior produção de massa seca de raízes para as mudas enxertadas no Passiflora alata o que era esperado devido ao comprimento das raízes destas plantas serem maiores, o maior volume formado de matéria seca é um indício de mudas, sadias e bem desenvolvidas.

De acordo a Figura 2 os diferentes tipos de copas utilizados nas enxertias mostraram diferenças significativas apenas para a característica de matéria seca da parte aérea.

A produção de massa seca da parte aérea dos maracujazeiros amarelo e roxo independentemente do porta-enxerto não diferiram entre si apresentando valores médios 4,69 e 4,38 g, mas significativamente superiores ao maracujazeiro-doce apresentando apenas 2,81g de massa seca. De acordo com Carneiro (1983), a massa seca da parte aérea é uma boa variável para indicar a capacidade de resistência das plantas aos fatores do meio, como altas temperaturas, ataque de pragas e principalmente absorção de luz. A massa seca das raízes tem sido reconhecida por diferentes autores como um dos mais importantes e melhores parâmetros para se estimar a sobrevivência e o crescimento inicial das mudas no campo (GOMES, 2001). 
Figura 2. Matéria seca da parte aérea (g) em mudas enxertadas de maracujazeiros amarelo, roxo e doce sobre o Passiflora alata e Passiflora cincinnata. Lavras - MG, 2010.

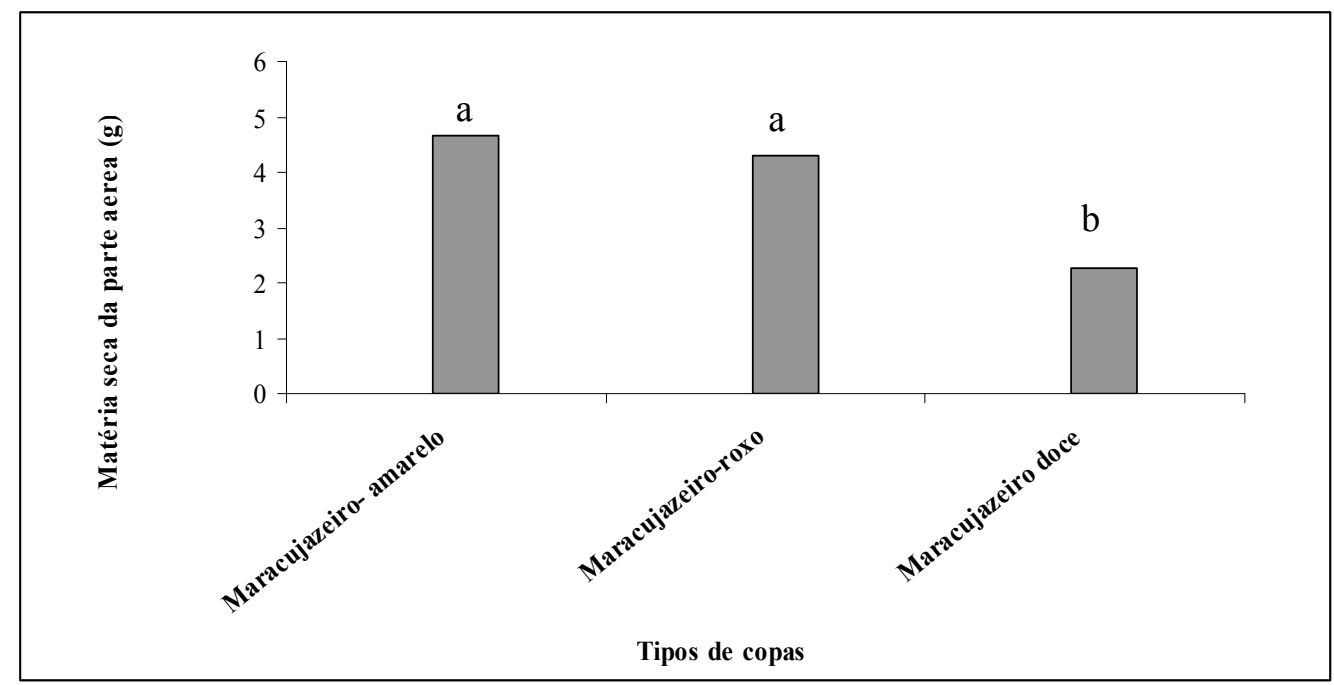

Letras distintas minúsculas na coluna diferem entre si, pelo teste de Tukey $\mathrm{P}<0,05)$.

Fonte: Elaboração dos autores.

\section{Conclusões}

Para formação de mudas de maracujazeiro através da enxertia o Passiflora alata sob o maracujazeiro amarelo, roxo e doce mostrou-se viável com maior porcentagem de pegamento.

Quando foi utilizado o Passiflora cincinnata como porta-enxerto para os maracujazeirosamarelo, roxo e doce ocorreu menor pegamento e desenvolvimento das mudas, não sendo recomendado seu uso como porta-enxerto na formação de mudas de maracujazeiro.

\section{Agradecimentos}

Os autores agradecem a Embrapa Mandioca e Fruticultura em Cruz das Almas, BA, pela concessão das sementes e ao CNPq pelo apoio financeiro.

\section{Referências}

AGUIAR, A. V.; SILVA, R. M.; CARDOSO, E. A.; MARAJÁ, P. B.; PIRES, H. G. Utilização de espécies de Passiflora spp. como porta-enxertos no controle de doenças do maracujazeiro. Agropecuária Científica no Semi-Árido, Campina Grande, v. 6, n. 4, p. 17-22, 2010.
ANTUNES, F. Z. Caracterização climática do estado de Minas Gerais. Informe Agropecuário, Belo Horizonte, v. 12, n. 138, p. 9-13, 1986.

APONTE, Y.; JÁUREGUI, D. Algunos aspectos de la biología floral de Passiflora cincinnata Mast. Revista de la Facultad de Agronomia, Maracaibo, v. 21, n. 3, p. 211 219, 2004.

ARAÚJO, F. P.; SILVA, N.; QUEIROZ, M. L. Divergência genética entre acessos de Passiflora cincinnata Mast. com base em descritores morfoagronômicos. Revista Brasileira de Fruticultura, Jaboticabal, v. 30, n. 3, p. 723-730, 2008.

CALDEIRA, M. V. W.; ROSA, G. N.; FENILLI, T. A. B.; HARBS, R. M. P. Composto orgânico na produção de mudas de aroeira-vermelha. Scientia Agraria, Curitiba, v. 9, n. 1, p. 27-33, 2008.

CARNEIRO, J. G. A. Variações na metodologia de mudas florestais afetam os parâmetros morfo-fisiologicos que indicam a sua qualidade. FUPEP Série Técnica, Curitiba, v. 12, p. 1-40, 1983.

CAVALCANTE, L. F.; SILVA, G. F.; GHEYI, H. R.; DIAS, T. J.; ALVES, J. do C.; COSTA, A. P. M. Crescimento de mudas de maracujazeiro amarelo em solo salino com esterco bovino líquido fermentado. Revista Brasileira de Ciências Agrárias, Recife, v. 4, n. 4, p. 414-420, 2009. 
CHAVES, R. C.; JUNQUEIRA, N. A. V.; MANICA, I.; PEIXOTO, J. R.; PEREIRA, A. V.; FIALHO, J. F.S. Enxertia de maracujazeiro-amarelo em estacas herbáceas enraizadas de espécies de passifloras nativas. Revista Brasileira de Fruticultura, Jaboticabal, v. 26, n. 1, p. 120-123, 2004.

CORRÊA, L. S.; CAVICHIOLI, J. C.; OLIVEIRA, J. C.; BOLIANI, A. C. Uso de câmara úmida em enxertia convencional de maracujazeiro-amarelo sobre três portaenxertos. Revista Brasileira de Fruticultura, Jaboticabal, v. 32, n. 2, p. 591-598, 2010.

FERREIRA, D. F. Programa computacional Sisvar ${ }^{\circledR}-$ UFLA. versão 5.3. Lavras: UFLA, 2010.

FISCHER, I. H.; LOURENÇO, S. A.; MARTINS, M. C.; KIMATI, H.; AMORIM, L. Seleção de plantas resistentes e de fungicidas para o controle da podridão do colo do maracujazeiro causada por Nectria haematococca. Fitopatologia Brasileira, Brasília. v. 30, n. 3, p. 250-258, 2005.

GOMES, J. M. Parâmetros morfológicos na avaliação da qualidade de mudas de Eucalyptus grandis, produzidas em diferentes tamanhos de tubetes e de dosagens de $N-P-K$. 2001. Tese (Doutorado em Ciências Florestais) Universidade Federal de Viçosa, Viçosa.

LENZA, J. B.; VALENTE, J. P.; RONCATTO, G.; ABREU, J. A. Desenvolvimento de mudas de maracujazeiro propagadas por enxertia. Revista Brasileira de Fruticultura, Jaboticabal, v. 31, n. 4, p. 1135-1140, 2009.

LIMA, A. A.; TRINDADE, A. V. Propagação. In: LIMA, A. A.; CUNHA, M. A. P. (Ed.). Maracujá: produção e qualidade na passicultura. Cruz das Almas: Embrapa Mandioca e Fruticultura, 2004. p. 15-35.
NOGUEIRA FILHO, G. C. ; RONCATTO, G.; RUGGIERO, C.; OLIVEIRA, J.; MALHEIROS, C. E. B. Estudo da enxertia Hipocotiledonar do maracujazeiroamarelo sobre dois porta-enxertos, através da microscopia de varredura. Revista Brasileira de Fruticultura, Jaboticabal, v. 32, n. 2, p. 647-652, 2010.

OLIVEIRA JÚNIOR, M. X.; SÃO JOSÉ, A. R.; REBOUÇAS, T. N. H.; MORAIS, O. M.; DOURADO, F. W. N. Superação de dormência de maracujá-do-mato (Passiflora cincinnata Mast.). Revista Brasileira de Fruticultura, Jaboticabal, v. 32, n. 2, p. 584-590, 2010.

RONCATTO, G.; OLIVEIRA, J. C.; RUGGIERO, C. Comportamento de maracujazeiros (Passiflora spp.) quanto à morte prematura. Revista Brasileira de Fruticultura, Jaboticabal, v. 26, n. 3, p. 552-554, 2004.

RONCATTO, G.; ASSIS, G. M. L. D.; OLIVEIRA, T. K. D.; LESSA, L. S. Pegamento da enxertia em diferentes combinações de variedades e espécies utilizadas como copa e como porta-enxertos de maracujazeiro. Revista Brasileira de Fruticultura, Jaboticabal, v. 33, n. 3, p. 791-797, 2011.

SANTOS, V. A.; RAMOS, J. D.; OLIVEIRA, M. C.; SILVA, E. A. Tipos de enxertia em diferentes idades de plantas de maracujazeiro. Revista Brasileira de Fruticultura, Jaboticabal, v. 33, n. 4, p. 1359-1363, 2011.

SILVA, R. M.; AGUIAR, A. V. M.; CARDOSO, E. A.; SOUZA, J. O. S.; OLIVEIRA, L. A. A. Enxertia interespecífica do maracujazeiro-amarelo sobre quatro porta-enxertos. Revista Verde, Mossoró, v. 6, n. 2, p. 119124, 2011.

SOUZA, G. L. F. M.; RIBEIRO, M. C. C.; CARDOSO, E. A.; PIRES, G. S.; SOUZA, P. A. Efeito da época de poda do sistema radicular no crescimento de mudas de Algarobeira. Revista Caatinga, Mossoró, v. 19, n. 3, p. 250-254, 2006. 